\title{
Factors affecting pulsatile ocular blood flow in normal subjects
}

\author{
F Mori, S Konno, T Hikichi, Y Yamaguchi, S Ishiko, A Yoshida
}

\begin{abstract}
Background-The factors that influence pulsatile ocular blood flow (POBF) were evaluated in normal subjects.

Methods-POBF was measured in 80 normal subjects using Langham OBF computerised tonometry. The effect of age, systolic and diastolic blood pressure, refractive error, intraocular pressure, and axial length on POBF was evaluated using multiple regression analysis.

Results-The mean (SD) POBF value was 593.3 (203.6) $\mu 1 / \mathrm{min}$ (range 290.7-1201.6). Of all the independent variables in the model, only the axial length was statistically significant $(p=0.008)$. The regression coefficient was negative, indicating that the axial length decreased with increasing POBF.

Conclusions-These data suggest that, in normal subjects, the POBF decreases as axial length increases. Choroidal blood flow may decrease as the axial length increases. The axial length may therefore be a major factor affecting POBF.

(Br F Ophthalmol 2001;85:529-530)
\end{abstract}

The determination of pulsatile ocular blood flow (POBF) by measuring intraocular pressure (IOP) pulse using Langham OBF computerised tonometry is a reliable way of evaluating choroidal blood flow. ${ }^{1-3}$ POBF has been evaluated in several ocular diseases including glaucoma, ${ }^{4}$ diabetic retinopathy, ${ }^{5}$ retinal pigmentosa, ${ }^{6}$ and age related macular degeneration. ${ }^{7}$ Several authors have reported that factors such as age, heart rate, blood pressure (BP), and axial length influence POBF. ${ }^{8-11}$

In this study we evaluated the factors that influence POBF in normal subjects. We determined the relation between POBF and age, systolic and diastolic BP, IOP, refractive error, and axial length using multiple regression analysis.

Department of Asahikawa Medical College, Midorigaoka Higashi 2-1-1-1, Asahikawa 078-8510, Japan

F Mori

S Konno

T Hikichi

Y Yamaguchi

S Ishiko

A Yoshida

Correspondence to:

Dr F Mori

morinao@d5.dion.ne.jp

Accepted 9 November 2000

\section{Materials and methods}

Eighty Japanese subjects (27 men, 53 women) were enrolled in the study. The characteristics of the subjects are summarised in Table 1 . Subjects with diabetes, heart disease, systemic hypertension, glaucoma, other ocular diseases, and a history of ophthalmic surgery were excluded from the study. Only one eye of each subject was randomly included. The study protocol was reviewed by the ethics committee of our institution and informed consent was obtained from all subjects. All procedures adhered to the tenets of the Declaration of Helsinki.
Table 1 Characteristics of the subjects

\begin{tabular}{lc}
\hline Variable & Mean (SD) [range] \\
\hline Age (years) & $62.9(12.2)[31-80]$ \\
Systolic BP (mm Hg) & $133.2(14.0)[104-156]$ \\
Diastolic BP (mm Hg) & $78.9(8.3)[62-94]$ \\
IOP (mm Hg) & $14.0(3.3)[9-20]$ \\
Refractive error (dioptres) & $0.2(1.7)[-5.0-4.6]$ \\
Axial length (mm) & $23.0(1.0)[20.6-26.6]$ \\
\hline
\end{tabular}

POBF was measured by Langham OBF computerised tonometry (Langham Ophthalmic Technologies, Timonium, MD, USA) with the subjects in the sitting position. Data were collected from each subject and the mean measurements were calculated from five representative pulses. Systolic and diastolic brachial arterial BP were measured with a sphygmomanometer with subjects in the sitting position, IOP was measured with a noncontact tonometer (CT-90, Topcon, Japan), and axial length was measured using A-scan biometric ultrasound (OcuScan, Alcon, Fort Worth, TX, USA). The refractive error was expressed as a spherical equivalent refraction obtained by autokeratorefractometry (KR7100, Topcon).

Multiple regression analysis was performed to determine the correlation between POBF and age, systolic and diastolic BP, IOP, refractive error, and axial length. The results are expressed as mean (SD).

\section{Results}

The range of POBF values is shown in Figure 1. The mean (SD) value of POBF was 593.3 (203.6) $\mu \mathrm{l} / \mathrm{min}$ (range 290.7-1201.6).

Table 2 shows the results of multiple regression analysis with $\mathrm{POBF}$ as the dependent variable. Of all the independent variables in the model, only the axial length was statistically significant $(p=0.008)$. The regression coefficient was negative, indicating that the axial length decreased with increasing POBF.

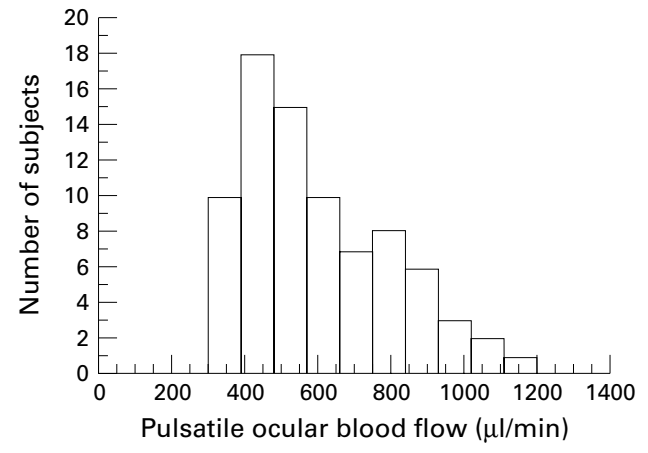

Figure 1 Distribution of pulsatile ocular blood flow in the study population $(n=80)$. 
Table 2 Results of multiple regression analysis

\begin{tabular}{lll}
\hline Variable & Regression coefficient & p Value \\
\hline Age & -0.14 & 0.24 \\
Systolic BP & -0.01 & 0.94 \\
Diastolic BP & -0.14 & 0.24 \\
IOP & -0.17 & 0.11 \\
Refractive error & 0.07 & 0.63 \\
Axial length & -0.38 & 0.008 \\
\hline
\end{tabular}

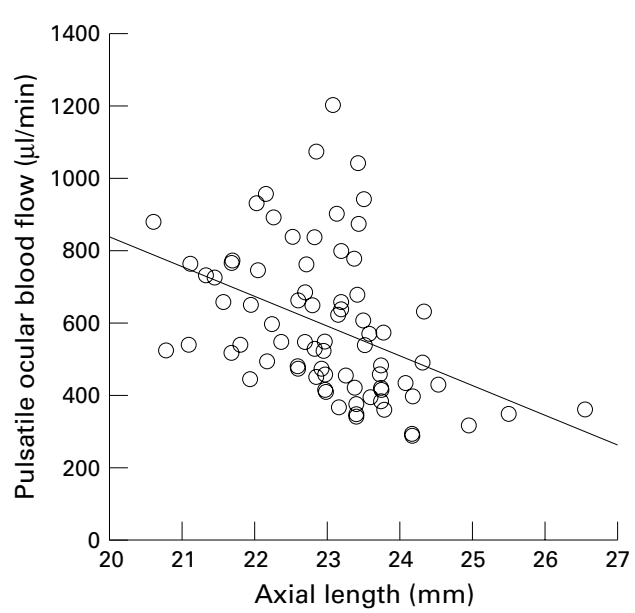

Figure 2 Relation between pulsatile ocular blood flow and axial length.

Stepwise elimination of non-significant variables led to an optimum model that included only axial length (coefficient $=-0.42$; $\mathrm{p}=0.0002$ ), indicating that it was the only variable contributing to the POBF. Figure 2 shows the relation between $\mathrm{POBF}$ and axial length.

\section{Discussion}

In this study the mean POBF value was $593.3 \mu \mathrm{l} / \mathrm{min}$ (range 290.7-1201.6). Several authors have reported mean POBF values between 444 and $803 \mu \mathrm{l} / \mathrm{min}$ in normal subjects. ${ }^{13-11}$ The values were consistent with those of the Japanese subjects in the present study.

The results of this study show that, as axial length increased, POBF decreased in normal subjects. In experimental chick models the choroidal blood flow decreased in myopic eyes with ocular enlargement induced by wearing goggles or corneal incisions. ${ }^{12-15} \mathrm{~A}$ reduction in ocular blood flow has been reported in severe myopia with increasing axial length. ${ }^{16}{ }^{17}$ The choroidal blood flow may decrease as the axial length increases.

The axial length was the major factor affecting POBF in the normal subjects in this study. Several authors have reported a relation between the ocular axial length and the ocular pulse amplitude and POBF. ${ }^{811} 1819$ They have suggested a number of possible reasons, other than decreasing choroidal blood flow, for the relation between axial length and the ocular pulse amplitude and POBF. Firstly, the ocular volume increases with increasing axial length so the effect of a small increase in volume caused by each bolus of blood may be reduced. Secondly, the negative correlation between scleral rigidity and ocular volume and axial length may affect the POBF. Honmura et al reported a significant correlation between scleral rigidity and axial length. ${ }^{20}$ We believe that we need to consider the relation between POBF, axial length, and scleral rigidity in the future.

Ravalico et al found that ocular pulse amplitude and POBF decreased in normal subjects with increasing age. ${ }^{10}$ However, these authors performed multiple regression analysis without considering refractive error or axial length. In our study we have determined the relation between POBF and age, BP, IOP, refractive error, and axial length using multiple regression analysis and found no significant regression between POBF and age.

The results of our study suggest that, as axial length increases, POBF decreases in normal subjects. The choroidal blood flow may decrease as the axial length increases. We conclude that axial length is the major contributory factor to POBF in normal subjects.

1 Langham ME, Farrell RA, O'Brien V, et al. Noninvasive measurement of pulsatile blood flow in the human eye. In: Lambrou GN, Greve EL, eds. Ocular blood flow in glaucoma. Amsterdam: Kugler \& Ghedini, 1989:93-9.

2 Alm A, Bill A. Ocular circulation. In: Moses R, Hat W, eds. Adler's physiology of the eye. 9th ed. St Louis: Mosby, 1992: Adler's physio.

3 Spraul CW, Lang GE, Ronzani M, et al. Reproducibility of measurements with a new slit lamp-mounted ocular blood flow tonograph. Graefes Arch Clin Exp Ophthalmol 1998; 236:274-9.

4 Langham ME, Farrel R, Krakau T, et al. Ocular pulsatile blood flow, hypotensive drugs and differential light sensitivity in glaucoma. In: Krieglstein GM, ed. Glaucoma update $I V$ 1991:162-72.

5 Langham ME, Grebe R, Hopkins S, et al. Choroidal blood flow in diabetic retinopathy. Exp Eye Res 1991;52:167-73.

6 Langham ME, Kramer T. Decreased choroidal blood flow associated with retinitis pigmentosa. Eye 1990;4:374-81.

7 Mori F, Konno S, Hikichi T, et al. Pulsatile ocular blood flow in age-related macular degeneration and the factors affecting normal subjects. Invest Ophthalmol Vis Sci 2000;41(Suppl):824.

8 James CB, Trew DR, Clark K, et al. Factors influencing the ocular pulse-axial length. Graefes Arch Clin Exp Ophthalmol 1991;229:341-4.

9 Trew DR, James CB, Thomas SHL, et al. Factors influencing the ocular pulse - the heart rate. Graefes Arch Clin Exp Ophthalmol 1991;229:553-6.

10 Ravalico G, Toffoli G, Pastori G, et al. Age-related ocular blood flow changes. Invest Ophthalmol Vis Sci 1996;37: 2645-50.

11 Ravalico G, Pastori G, Croce M, et al. Pulsatile ocular blood flow variations with axial length and refractive error. Ophthalmologica 1997;211:271-3.

12 Shih YF, Fitzgerald ME, Norton TT, et al. Reduction in choroidal blood flow occurs in chicks wearing goggles that induce eye growth toward myopia. Curr Eye Res 1993;12: 219-27.

13 Shih YF, Fitzgerald ME, Reiner A. Choroidal blood flow is reduced in chicks with ocular enlargement induced by corneal incisions. Curr Eye Res 1993;12:229-37.

14 Reiner A, Shih YF, Fitzgerald ME. The relationship of choroidal blood flow and accommodation to the control of choroidal blood flow and accommodation to
ocular growth. Vision Res 1995;35:1227-45.

15 Shih YF, Fitzgerald ME, Cuthbertson SL, et al. Influence of Shih YF, Fitzgerald ME, Cuthbertson SL, et al. Influence of
ophthalmic nerve fibers on choroidal blood flow and ophthalmic nerve fibers on choroidal blood flow an
myopic eye growth in chicks. Exp Eye Res 1999;69:9-20.

16 Galassi, Sodi A, Ucci F, et al. Ocular haemodynamics in glaucoma associated with high myopia. Int Ophthalmol 1998;22:299-305.

17 Akyol N, Kukner AS, Ozdemir T, et al. Choroidal and retinal blood flow changes in degenerative myopia. Can $7 \mathrm{Oph}$ thalmol 1996;31:113-9.

18 To'mey KF, Faris BM, Jalkh AE, et al. Ocular pulse in high myopia: a study of 40 eyes. Ann Ophthalmol 1981;13:56971.

19 Shih YF, Horng $\mathrm{IH}$, Yang $\mathrm{CH}$, et al. Ocular pulse amplitude in myopia. F Ocul Pharmacol 1991;7:83-7.

20 Honmura S. Studies on the relationship between ocular tension and myopia: II. Ocular tension, ocular rigidity, aqueous outflow and aqueous secretion in myopic eyes. Acta Soc Ophthalmol fpn 1968;72:74-82. 